Lozano-Sanfèlix, Neus.

Profesora, Universitat Jaume I, Departamento de Educación, Grupo de investigación RAVE (Recerca en Arts Visuals i Educació).

\title{
Saberes y aprendizajes en la construcción de la identidad y la subjetividad de la artista en la Universitat (Politècnica de València) $^{1}$
}

\section{Knowledge(s) and learning(s) in the construction of identity and subjectivity of the artist to the University (Politècnica de València)}

TIPO DE TRABAJO:

Comunicación.

PALABRAS CLAVE:

Universidad, Práctica artística, Investigación artística, cartografía crítica, conocimiento situado.

KEY WORDS :

University, Artistic practice, Artistic research, critical cartography, situated knowledges.

RESUMEN.

¿Hasta que punto la universidad, como dispositivo y situación, ha construido nuestra identidad como artistas? Esta es la pregunta de la que parte la experiencia que presentamos a continuación, una práctica artística que atraviesa la idea de cartografía para construir un relato alternativo al discurso dominante sobre la universidad y que se fundamenta a partir de otros saberes, considerados como subalternos por la propia institución. El relato se construye a partir de relacionar diferentes documentos de diversa índole (anécdotas, publicaciones, conversaciones, canciones, noticias de prensa, etc.) con el fin de desvelar sus "otros" significados, aquellos aprendizajes que no figuran de manera oficial en el currículum. Repensar nuestra propia formación nos sirve, como estrategia y detonante, para repensar nuestros marcos referenciales y evidenciar la ideología implícita en las dinámicas y estructuras de la Universidad.

\section{ABSTRACT.}

What knowledge? and what learning?: higher education as a space for the production and the transmission of knowledge -as well as regarding artistic practice. To what extent has higher education - as a device and situation- built our identity as artists? This is the question from which stems the experience we present below, an artistic practice that goes through the idea of cartography to build an alternative narrative to the prevalent discourse about university, and founded upon other kind of knowledge, which is considered as subordinate by the institution itself. This narrative is constructed by connecting documents of diverse kinds (anecdotes, publications, conversations, songs, press news, etc.) and generating a narrative thread that unveils their "other" meaning, which becomes a learning missing from the official curriculum.

\footnotetext{
${ }^{1}$ Este título es un guiño a la tesis doctoral de AMENGUAL QUEVEDO, I. 2012. Saberes y aprendizajes en la construcción de la identidad y la subjetividad de una educadora de museos: El caso del proyecto "Cartografiem-nos" en el Museo Es Baluard. Carla Padró Puig, directora. Tesis doctoral, Universitat de Barcelona. [Consulta: 8 de marzo 2016]. Disponible en: http://hdl.handle.net/2445/36700. Ésta fue una de las herramientas utilizadas como detonante de la investigación y la práctica artística que aquí se presentan.
} 
Rethinking our own education serves us as a strategy and a starting point to rethink our reference frames and thus make evident the implicit ideology within the dynamics and the structure of higher education as an idea and an institution.

\section{CONTENIDO.}

\section{(Introducción: Introducción / 4'33"}

Después de su paso por la cámara anecoica de la Universidad de Harvard, John Cage reelabora su idea de silencio y compone 4'33" (cuatro, treinte y tres), el silencio deja de ser silencio, para ser precisamente sonido escuchado. En palabras de Carmen Pardo (2001), en su libro la La escucha oblicua, Cage nos desvela con esta pieza, precisamente, la sonoridad del silencio. Si hasta entonces, el silencio como elemento estructural en una composición era materia prima que servia como preludio a las notas de algun instrumento, como complemento efectista; en la pieza de Cage, es precisamente el silencio el protagonista de la composición, intensificando, a través de él y de su densidad, la escucha atenta como experiencia sonora en si, mucho más compleja si cabe que la entendida como experiencia musical.

El silencio, en la pieza de Cage, y como metáfora, desvela aquello que precisamente ocultan las notas en la composición, los sonidos imperceptibles que construyen otra experiencia narrativa, el "silencio sonoro que siempre coexiste en el espacio de ejecución de una obra" (Pardo 2001, p. 39). Que te transporta al aquí y ahora, al tomar conciencia del espacio, ¿porque no? también político. Algo parecido pasa con los documentos escritos, las pausas, los silencios, que marcan los signos de puntuación que permiten a la persona lectora comprender el significado y la entonación del texto escrito. En el que la jerarquización del relato que se narra, su organización estructural, su gramatización ${ }^{2}$, pasa por alto detalles que bien podrían hacernos cuestionar nuestra compresión del mismo o la lógica de los sucesos que cuenta. Esta idea, de información sesgada, es visible igualmente en los documentos visuales, puesto que como ya sabemos una imagen, aunque esta sea fotográfica, siempre es una construcción. Podríamos apelar a esta idea del silencio, a este aquí y ahora, a la idea de lo local frente a los global, desde las palabras que suscribe Donna Haraway (1995), que ningún conocimiento puede desligarse de su contexto ni de la subjetividad de quien lo emite, apelando de este modo a un conocimiento situado.

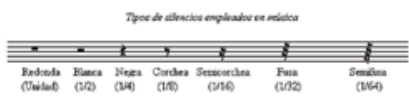

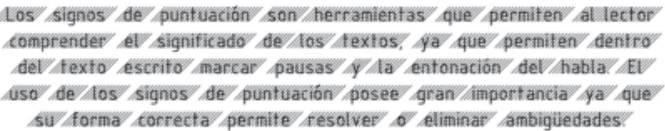

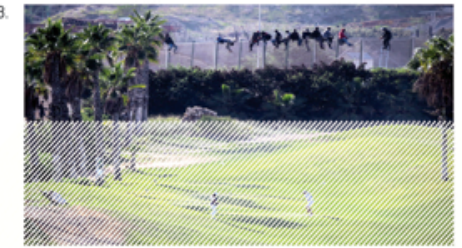

Ilustración 1: En la imagen podemos ver representado el silencio en tres formatos distintos: el empleado en música (1), el empleado en el texto (2) y en la imagen (3) Cita visual: Fotografía de José Palazón, Melilla, 2014.

Si asumimos la complejidad del silencio como sonoridad y materia prima existente, si aceptamos el silencio como parte de la jerarquización y la direccionalidad del discurso en la contrucción del relato histórico, en la aproximación a la comprensión de la realidad, no puede ser sinó sintiéndonos partícipes en la construcción de nuestros saberes y cuestionando nuestros marcos de referencia que debamos procurarnos espacios de pensamiento ${ }^{3}$ (Keith 2009), de refugio crítico (Boogerd 2000), de resistencia críticadeconstructiva (Derrida 1998). Para que éstos nos provean de las condiciones necesarias para re-pensarnos. Y si nos adeherimos a la idea de Derrida (1998, pp. 12-13) de una universidad sin condición, con “... derecho a la deconstrucción como derecho incondicional a plantear cuestiones críticas no sólo a la história del hombre sino la historia misma de la noción de crítica, a la forma y a la autoridad de la cuestión, a la forma interrogativa del pensamiento", es necesario en la construcción de nuestros saberes y subjetividades, como artistas, plantearnos y tomar partido en responder, aquí y ahora, a la pregunta de ¿Hasta qué punto la universidad como dispositivo y situación ha construido nuestra identidad como artistas? Más aún, en nuestro contexto, en el estado español, si tomamos en cuenta dos advertencias: (1) la de Whitney Chadwick $(1992$, p. 8) en Mujer Arte y Sociedad, el histórico sometimiento de los intereses de las mujeres a la academia y a "una historia del arte generalmente hilvanada siguiendo los hitos de los "viejos maestros" y de las "obras

\footnotetext{
${ }^{2}$ Hacemos un guiño al texto de Pardo (2001 p. 7) cuando utiliza el concepto de gramatización para hacer referencia a una de las denuncias de Cage en sus composiciones, mostrar que "hay una escucha de la música que está gramatizada, que lo que se denomina música se corresponde con el deseo de un oído intelectivo".

${ }^{3}$ SHEIKH, S. 2009. "Objects of Study of Comodification of Knowledege? Remarks on Artistic Research", en Art\&Research, 2(2), pp. 1-8. ISSN 1752-6388 [Consulta: 8 marzo 2017]. Disponible en http://www.artandresearch.org.uk/v2n2/pdfs/sheikh.pdf. Citado por KAUFMANN, T. 2011. "Arte y conocimiento: rudimentos para una perspectiva decolonial", en Transversal, 3. ISSN 1811-1696 [Consulta: 8 marzo 2017]. Disponible en: http://eipcp.net/transversal/0311/kaufmann/es/print
} 
maestras" (y añadimos: ahora también de los nuevos maestros ${ }^{4}$ )" y, (2) Un proceso de globalización (e internacionalización académica) imparable que no deja espacio para recuperar la memoria histórica local, que nos interroga sobre los efectos de una dictadura (la franquista) cuyo principal objetivo fue acabar con el proyecto educativo de la Segunda República (Claret 2006) y que entre sus obsesiones estuvo la de impedir toda permeabilidad intelectual que viniera de la Europa foránea. Siendo esto así, no podemos obviar los acontecimientos que forjaron nuestras instituciones educativas de hoy.

De este modo, se hace inevitable reflexionar sobre la universidad como espacio de (re-)producción, intermediación y transmisión de saberes en torno a la práctica artística. Poniendo especial atención en los procesos de normalización y construcción de nuestra identidad. Que es una acción necesaria para construirnos y empoderarnos en la investigación con los propios medios, sin tener que obedecer a las constricciones de la academia, que Sheikh $(2006)^{5}$ identifica como una de las luchas de los artistas del pasado. Estos procesos de normalización se deben, en gran parte, a situaciones, tensiones y percepciones que intervienen en nuestro sistema comprensivo, en nuestra red conceptual de la realidad; pero que en su mayoria son poco identificables y/o detectables, puesto que en cierto modo forman parte ya del conjunto de creencias, preconcepciones, mitos, prejuicios que albergamos de la institución educativa, la cual guarda una obvia vinculación con la historia social y cultural del contexto en que se encuentra y por tanto del relato que se construye desde y en torno a ella en la producción de conocimiento y saber.

La experiencia que presentamos a continuación es el resultado de la experimentación de la práctica artística titulada La universidad como espacio de producción y transmisión de saberes [en torno a la construcción de la identidad del artista y su práctica] (2015), la cual tenía como objeto cuestionar y dar respuesta a los interrogantes que acabamos de plantear desde un conocimiento situado. Para ello, (1) en primer lugar, presentaremos el contexto en que se origina la práctica artística, el taller de Rogelio López Cuenca y la investigación desarrollada durante la elaboraciónde la investigación de la tesis doctoral Enseñanza universitaria y práctica artística. Criterios para su experimentación, activación e intermediación desde un saber situado (Lozano-Sanfèlix 2015a) que explora, desarrolla y experimenta con posibles estrategias con el objetivo de impulsar un cambio en las metodologías de enseñanza-aprendizaje de la práctica artística; (2) realizaremos una descripción de la metodología seguida, los procesos de conceptualización y formalización, y (3) como conclusión, presentaremos algunas reflexiones que surgen a partir de la propia experiencia en la construcción del relato, el cual suscitará una respuesta que nos permitirá expandir y repensar la identidad y subjetividad como artistas en el contexto de la Universidad (Politécnica de Valencia).

(Desarrollo: La universidad como espacio de producción y transmisión de saberes [en torno a la construcción de la identidad del artista y su práctica])

\section{Origen.}

La práctica artística que presentamos se inicia con la participación en el taller No/W/here: Valencia ${ }^{6}$, a cargo de Rogelio López-Cuenca en la Facultad de Bellas Artes de Valencia en abril del 2015. En él se nos propuso a un grupo de estudiantes, experimentar en torno a la idea de la práctica artística de la cartografía como investigación situada (López-Cuenca 2016). Cada participante eligió un espacio de la ciudad, en nuestro caso el objeto de estudio fue la universidad. El proceso de investigación duró desde el 20 de abril de 2015 hasta el 7 de octubre de 2015, día en que se inauguró la exposición Radical Geographics (7.10.2015 - 14.02.2016) en el Institut Valencià d'Art Modern (IVAM).

\section{Metodología, conceptualización y formalización.}

Entre las directrices que se siguieron para la elaboración de la cartografía, podemos identificar las siguientes: (1) la posibilidad de no restringir nuestra investigación a unos resultados concretos propuestos de antemano, sino encontrar puntos de encaje y conexión entre diferentes ideas (...imágenes, objetos, etc.) ; (2) la no jerarquización de las fuentes de información ni la descalificación de documentación que a priori no tuviera una vinculación evidente con nuestro objeto de investigación, dando la posibilidad de este modo de dar con situaciones inprevisibles que producieran condiciones de posibilidad (Rogoff 2007); (3) utilización de documentación de todo tipo de formatos (fotografías, planos, citas textuales, noticias de prensa, canciones, definiciones, etc.), la cual podía tener

\footnotetext{
${ }^{4}$ Sobre la mujer artista en la academia hoy: LOZANO-SANFĖLIX, N. 2015. "¿Puede hablar la artista?". En: Silvia Marí Martí (Ed.) Artistaas: Violencias, afectos, diálogos, creaciones. Teruel: Universidad de Zaragoza, pp. 57-61. ISBN 978-84-608-7785-1.

${ }_{5}^{5}$ SHEIKH, S. 2006. "Spaces for Thinking. Perspectives on the Art Academy", en Texte zur Kunst, 62, pp. 191-196. [Consulta: 8 marzo 2017]. Disponible en http://backissues.textezurkunst.de/NR62/SIMON-SHEIKH en.html. Citado por KAUFMANN, T. 2011. "Arte y conocimiento: rudimentos para una perspectiva decolonial", en Transversal, 3. ISSN 1811-1696 [Consulta: 8 marzo 2017]. Disponible en: http://eipcp.net/transversal/0311/kaufmann/es/print

${ }^{6}$ El taller No/W/here: Valencia se desarrolló entre el 20-24 de abril de 2015 en la Facultad de Bellas Artes de la Universitat Politècnica de València. En él se propuso analizar un conjunto de metodologías aplicadas por Rogelio López-Cuenca en algunos de sus proyectos de intervención artística para la esferea pública y se nos brindó la oportunidad de participar en el proyecto conel mismo título y que formó parte de la exposción Radical Geographics que la Galería G6 del IVAM (Institut Valencià d'Art Modern) dedicó a López-Cuenca. El proceso de investigación duró desde el 20 de abril de 2015 hasta el 7 de octubre de 2015, día en que se inauguró la exposición.
} 
diferentes utilidades en cuanto a la construcción de la cartografía (formato, datación, contenido, descripción, color, forma, etc.); (4) la rigurosa documentación, registro y archivo de toda la información recogida; (5) el diseño de una estructura rítmica que sirviera como mapa previo a la elaboración de la cartografía y su formalización.

El proceso de investigación y elaboración de la cartografía culminó con la elaboración de tres mapas que se pueden entender como capas de un mismo proyecto: (1) El primero contiene la información recogida y el dibujo de los vínculos que se fueron trazando a medida que la investigación avanzaba y se expandía hacia lugares insospechados; (2) el segundo corresponde a la estructura rítmica, cuya secuenciación nos sirve para entender y conectar la narración con el relato, su coherencia, el mapa del mapa, y; (3) el tercer mapa es el conjunto de la información organizada tanto conceptual como formalmente como resultado de la experiencia.

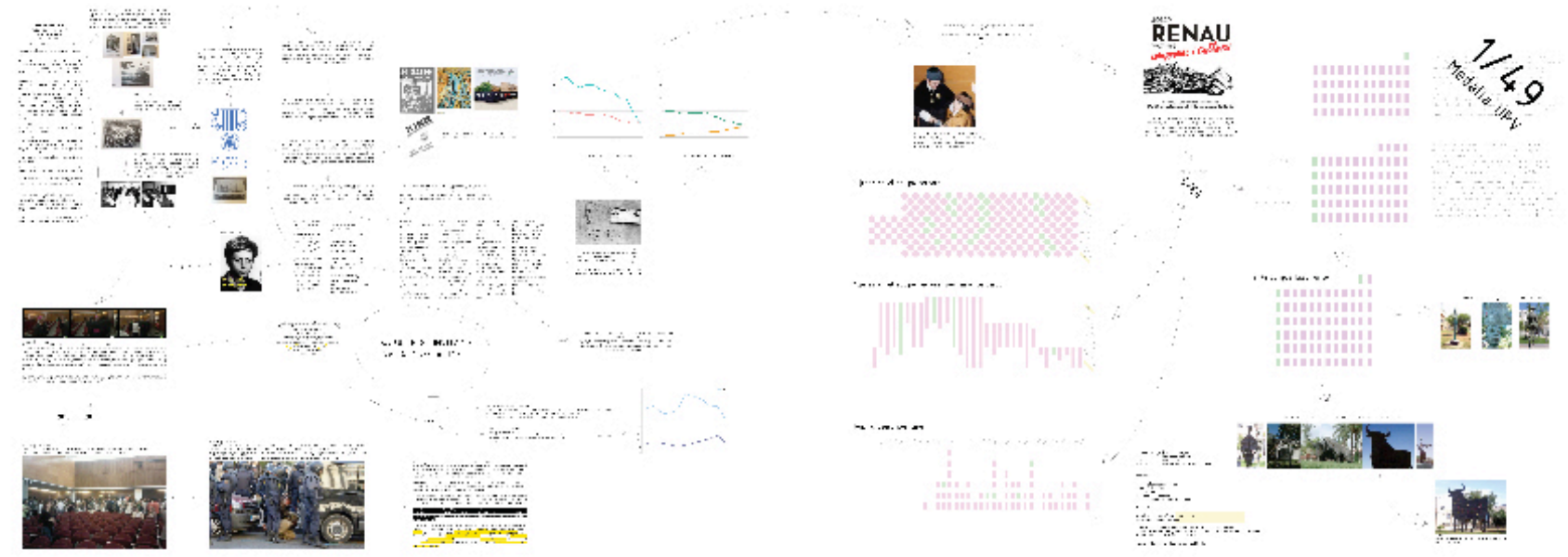

Ilustración 2: Mapa 01. Investigación y conexiones entre la información y los documentos encontrados.

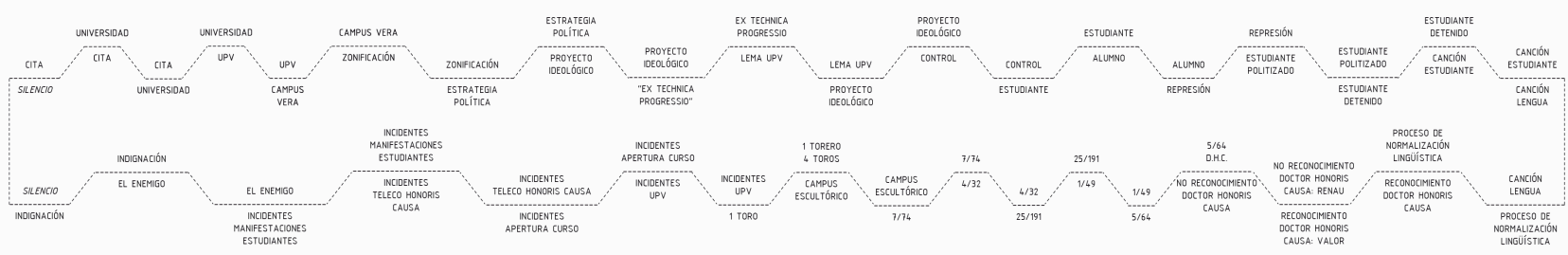

Ilustración 3: Mapa 02. Estructura rítmica. 

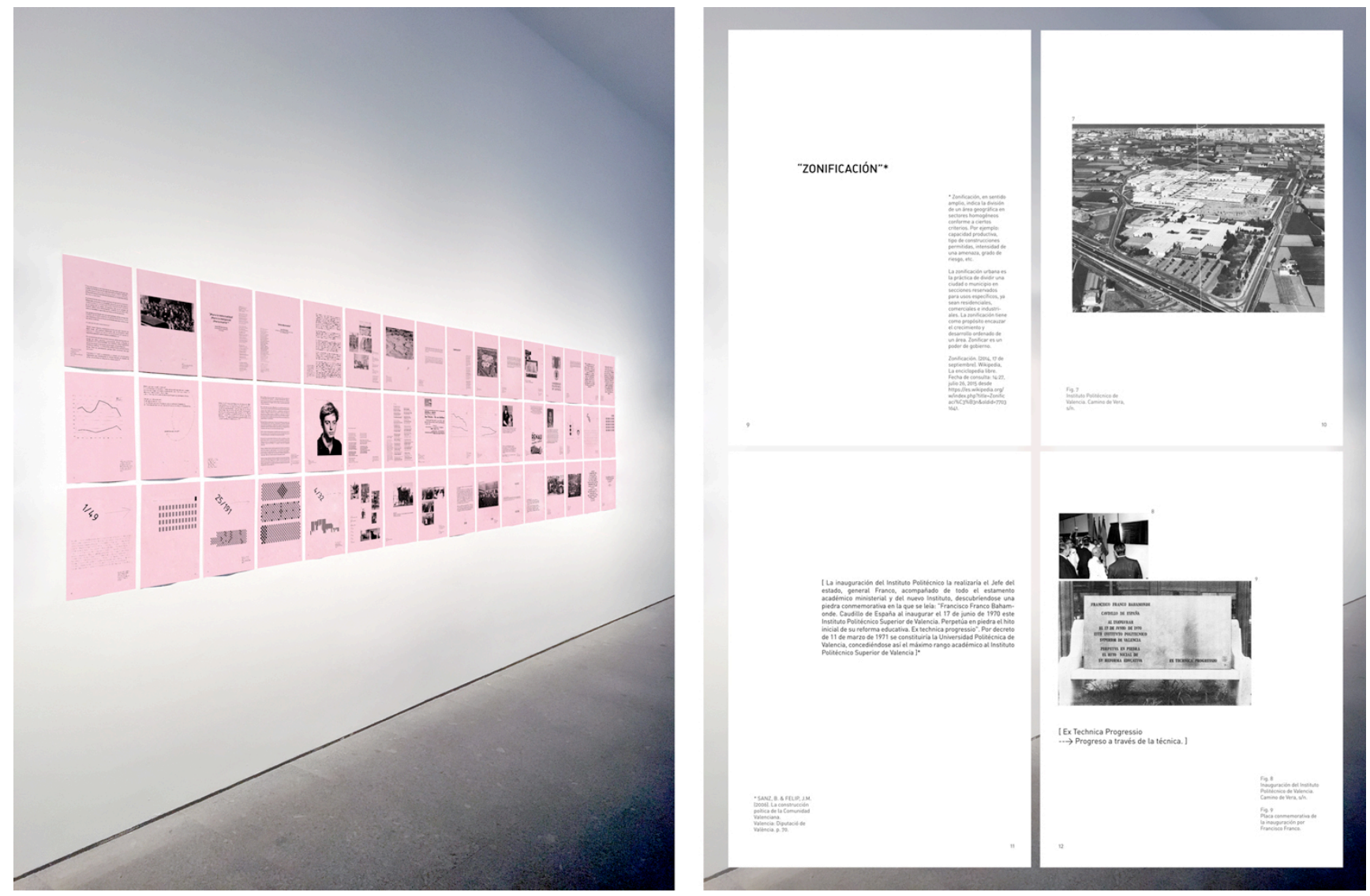

Ilustración 4: Vista panorámica y detalle pp. 9-12: Neus Lozano-Sanfèlix, La universidad como espacio de producción y transmisión de saberes [en torno a la construcción de la identidad del artista y su práctica], 2015.

El formato adoptado para la exposición de la cartografía (mapa 03) consiste en 54 hojas A4 maquetadas e impresas en blanco y negro sobre papel de color. En cada una de ellas podemos ver distintos documentos. Éstos han sido elegidos siguiendo la estructura rítmica y la secuenciación adoptadas (mapa 02). En cada hoja ha sido anotada la fuente de donde se ha obtenido la información. Los criterios para la materialización son el bajo coste de su producción y la fácil reproductibilidad y archivo de la misma.

\section{(Conclusiones: Conclusiones / Relato: Saberes y aprendizajes)}

De los relatos posibles que podríamos extraer a partir de la cartografía elaborada, uno de ellos diría así:

01. Tras el golpe de estado al gobierno de la Segunda República en julio de 1936, se crea la Oficina de Prensa y Propaganda dirigida por José Millán Astray, ésta será el organismo de censura y control de la prensa y la edición, y la encargada de elaborar los listados del personal docente sometido a depuración (asesinado, cesado, encarcelado, trasladado, inhabilitado y sancionado).

02. Universidad Politécnica de Valencia (1971), integra la titulación de Licenciado/a en Bellas Artes. [...] El campus se encuentra alejado de cualquier núcleo importante de población. La zonificación urbana es la práctica de dividir un espacio urbano por usos y tiene como propósito encauzar el crecimiento y desarrollo ordenado de un área. [ORdenACIÓn TeRRITORIAL COMO PROYeCto IDEOLógico].

03. En la inauguración presidida por Francisco Franco se descubre una piedra conmemorativa: "Francisco Franco Bahamonde [...] Perpetúa en piedra el hito inicial de su reforma educativa. Ex technica progressio [PROGRESO A tRAVÉs de LA TÉCNICA / PROYeCto IDEOLóGICO].

04. En la universidad estaban prohibidas: las asambleas, reuniones, la colocación de carteles informativos en las 
paredes, las actividades culturales, musicales, conferencias, mesas redondas [Privación y AUTONOMía / PROYECTO IDEOLÓGICO / VINCULACIÓN CON LA VIDA CULTURAL Y ACADÉMICA].

05. Ante esta situación, la autoridad académica no existe más que para colaborar en las tareas represivas, adoptando "una actitud totalmente servil y colaboracionista". El control de asistencia permitía excluir al estudiante del derecho de ser examinado [PRIVACIón DE DERECHOS / PROYecto IDEOLógICo VINCULADO A LA VIDA PRIVADA]. Si un estudiante era procesado por el TOP (Tribunal de Orden Público), era privado del derecho de entrada y permanencia en la Universidad. Aunque los hechos por los que se sancionaba hubieran ocurrido fuera del ámbito universitario y no hubieran afectado al orden y disciplina académica.

07. Enrique Ruano Casanova (1948 - Madrid, 20 de enero de 1969), Estudiante de Derecho y militante antifranquista español, muerto en circunstancias no esclarecidas bajo custodia de la Brigada Político Social, la policía política del régimen franquista. Lluís Serrahima compone la poesía que en 1977 María del Mar Bonet cantará: Què volen aquesta gent? (CANCIÓn - CULTURA / SABERES SUBALTERNOS).

08. Entre 2002 y 2014 la oferta de créditos en lengua valenciana en la Facultad de Bellas Artes pasa de un $8 \%$ a $4 \%$ del total. En 1999 nombran Doctor Honoris Causa a Enric Valor i Vives, narrador y gramático. Al finalizar el curso 2003-2004 desaparece la figura de Vicerrector/a de Promoción y Normalización Lingüística. En 1979 la junta de Gobierno de la UPV rechaza por primera y única vez una propuesta de Doctor Honoris Causa: Josep Renau. (Lengua materna / SAberes Subalternos).

09. Renau fue Director General de Bellas Artes durante la Segunda República española, fue quien solicitó la colaboración de Ángel Ferrant para la "reorganización de la enseñanza artística". (MEMORIA HISTÓRICA / SABERES SUBALTERNOS)

10. Entre 1988 y 2014 de los 64 nombramientos a Doctor Honoris Causa, sólo 5 fueron mujeres: una actriz, una princesa, una cantante, una bailarina y coreógrafa y una cosmonauta [GÉNERo / RoLES].

11. Entre los cargos del Rectorado, entre 2001 y 2012, solo 25 fueron ocupados por mujeres, el resto por 191 hombres. De 25 cargos ocupados por mujeres, se trató de 4 mujeres que continuaban en el puesto o que cambiaban de área. Sólo hay 7 mujeres artistas frente a 74 hombres en el Campus Escultórico de la UPV. (GÉNERO / POLÍTICAS) 

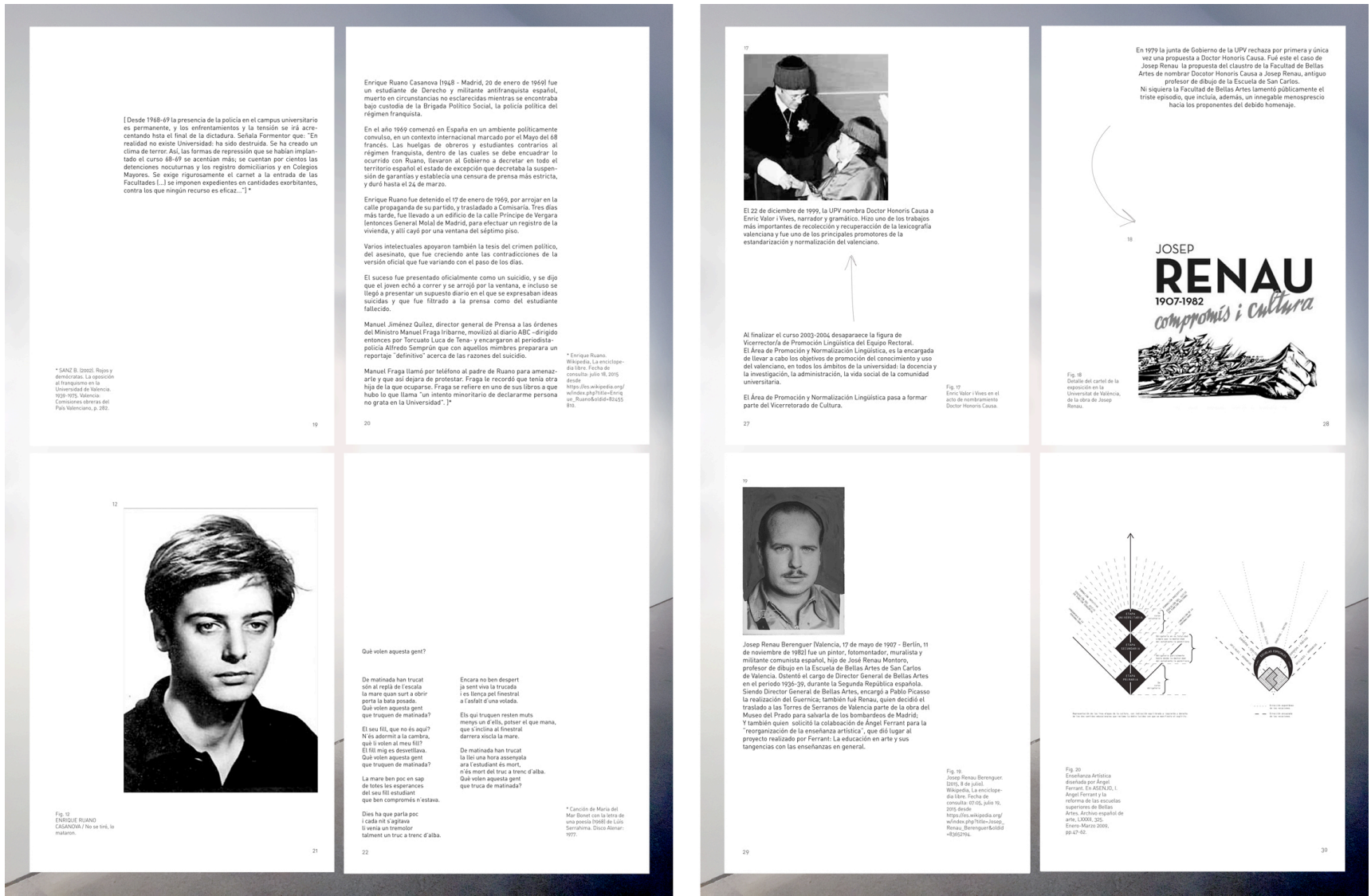

Ilustración 5: Detalle pp. 19-22 y 27-30: Neus Lozano-Sanfèlix, La universidad como espacio de producción y transmisión de saberes [en torno a la construcción de la identidad del artista y su práctica], 2015.

12. En el acto de entrega del Teleco Honoris Causa a la delegada del Gobierno en la Comunidad Valenciana, mayo de 2012, 80 personas entran en la Sala del Paraninfo al grito de "delegada dimisión". Tres meses antes, la Delegada del Gobierno tildaba de anecdóticas la detención de 38 estudiantes, 8 de ellos menores, durante las cargas policiales durante las manifestación por una educación pública y de calidad. Solo un grupo de ex-alumnos del IES Lluís Vives de Valencia hace publica en la prensa en la que manifiesta su disconformidad con actuación del gobierno. "A veces, quedarse callado equivale a mentir, porque el silencio puede ser interpretado como aquiescencia" Unamuno, Universidad de Salamanca, 12/10/1936. (PolíticA Del Silencio)

Si bien esta breve narración no representa la diversidad de información que encontramos en la cartografía, bien es cierto que no podemos disociar el conocimiento sobre el contexto y nuestra propia subjetividad como lectoras, en la selección e interpretación de la documentación, las relaciones que establecemos entre los datos, y nuestras preferencias y prioridades. No obstante hay que evidenciar que una mirada reflexiva a nuestro entorno, expande nuestros marcos referenciales, y que la práctica artística ensancha los caminos del acceso al conocimiento. A la vez que necesariamente se interroga también sobre los efectos sociales y económicos de su propia práctica, una práctica que cada vez más se ve desprestigiada en muchos ámbitos, especialmente el educativo.

Es necesario mostrar las contradicciones de la institución educativa, detectar la deslocalización y pérdida de significados, la mutación de algunos de ellos y las justificaciones que se utilizan, como por ejemplo para volver a implantar el registro de la asistencia, el uso de la palabra estudiante, los contenidos y referencias que se utilizan, en definitiva, la necesidad de organizarse colectivamente, para transformar las dinámicas y los saberes de la institución. 

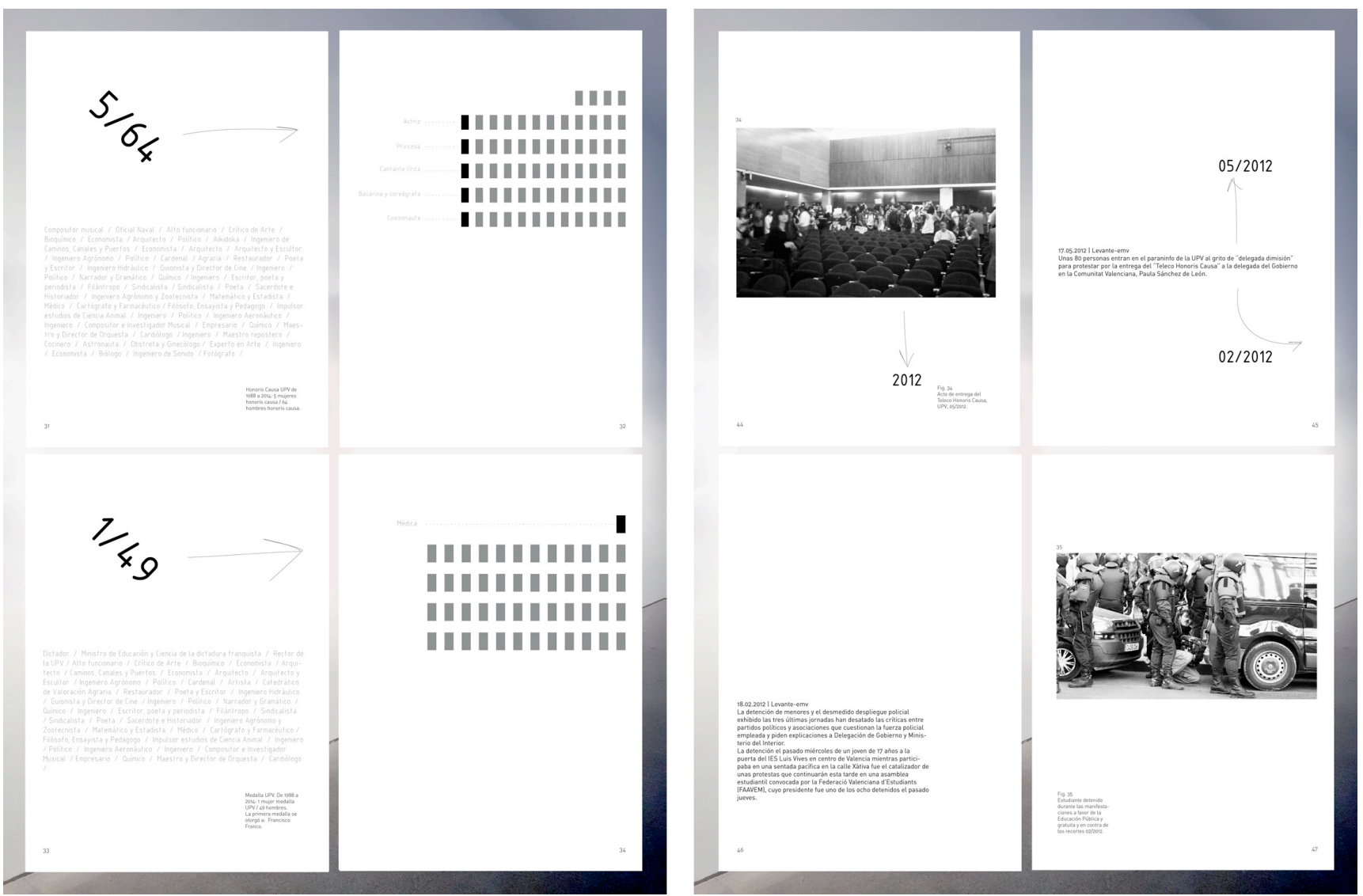

Ilustración 6: Detalle pp. 31-31 y 44-47. : Neus Lozano-Sanfèlix, La universidad como espacio de producción y transmisión de saberes [en torno a la construcción de la identidad del artista y su práctica], 2015.

En el catálogo de Un saber realmente útil (What, How \& for Whom et al. 2014, p. 19), se recoge que "El concepto de saber realmente útil surgió a comienzos del siglo XIX, cuando los obreros tomaron conciencia de la necesidad de la autoformación. En las décadas de 1820 y 1830, las organizaciones obreras de Reino Unido introdujeron esta frase para describir el corpus de conocimientos que abarcaba diversas disciplinas poco prácticas como la política, la economía y la filosofía, caracterizadas como opuestas a los "saberes útiles", proclamados como tales por los empresarios, que habían empezado a invertir cada vez más en el desarrollo de sus negocios mediante la financiación de programas formativos destinados a los obreros en competencias aplicables y disciplinas como la ingeniería, la física , la química o las matemáticas". Contraponemos aquí el saber subalterno, como el académicamente marginado, que como hemos podido observar puede ser realmente útil.

\section{FUENTES REFERENCIALES.}

AMENGUAL QUEVEDO, I. 2012. Saberes y aprendizajes en la construcción de la identidad y la subjetividad de una educadora de museos: El caso del proyecto "Cartografiem-nos" en el Museo Es Baluard. Carla Padró Puig, directora. Tesis doctoral, Universitat de Barcelona. [Consulta: 8 de marzo 2016]. Disponible en: http://hdl.handle.net/2445/36700.

BREA, J.L. 2004. "La universidad del conocimiento y las nuevas humanidades", en Estudios Visuales, 2, pp. 133-154. [Consulta: 8 de marzo 2017]. Disponible en: http://www.estudiosvisuales.net/revista/pdf/num2/universidad.pdf

BOOGERD, D. 2000. "De Ateliers, el instituto de los artistas como refugio crítico", en Inventario, revista para el arte, 6, pp. 157-164. ISSN 1575-9970

CHADWICK, W 1992. Mujer, arte y sociedad. Barcelona: Ediciones Destino. ISBN: 84-2332-2475. 
CLARET MIRANDA, J. 2006. El atroz desmoche: la destrucción de la Universidad española por el franquismo, 1936-1945. Barcelona: Editorial Crítica. ISBN 84-8432-7604.

DERRIDA, J. 2002. La universidad sin condición. Madrid: Trotta. ISBN 84-8164-533-8.

HARAWAY, D.J. 1995. Ciencia, cyborgs y mujeres. La reinvención de la naturaleza. Valencia: Ediciones Cátedra, Universidad de València e Instituto de la Mujer. ISBN 84-376-1392-2.

KAUFMANN, T. 2011. "Arte y conocimiento: rudimentos para una perspectiva decolonial", en Transversal, 3. ISSN 1811-1696 [Consulta: 8 marzo 2017]. Disponible en: http://eipcp.net/transversal/0311/kaufmann/es/print

LÓPE -CUENCA, R. 2016. Yendo leyendo, dando lugar. De la práctica artística de la cartografía como investigación situada. Juna Pablo Wert Ortega, director. Tesis doctoral, Universidad de Castilla-La Mancha.

LO ANO-SANFÈLIX, N. 2015. Enseñanza universitaria y práctica artística. Criterios para su experimentación, activación e intermediación desde un saber situado. Amparo Carbonell Tatay y Trinidad Gracia Bensa, directoras. Tesis doctoral, Universitat Politècnica de València. Doi:10.4995/Thesis/10251/59476. [Consulta: 8 de marzo 2016]. Disponible en: http://hdl.handle.net/10251/59476

LO ANO-SANFÈLIX, N. 2015. "¿Puede hablar la artista?". En: Silvia Martí Marí (Ed.) Artistaas: Violencias, afectos, diálogos, creaciones. Teruel: Universidad de aragoza, pp. 57-61. ISBN 978-84-608-7785-1.

PARDO SALGADO, C. 2001. La escucha oblicua: una invitación a Jonh Cage. Valencia: Universitat Politècnica de València. ISBN 84-9705039-8

ROGOFF, I. 2007. La academia como potencialidad. Zehar: revista de Arteleku-ko aldizkaria, 60-61, pp. 10-15.

SHEIKH, S. 2006. "Spaces for Thinking. Perspectives on the Art Academy", en Texte zur Kunst, 62, pp. 191-196. [Consulta: 8 marzo 2017]. Disponible en http://backissues.textezurkunst.de/NR62/SIMON-SHEIKH_en.html.

SHEIKH, S. 2009. "Objects of Study of Comodification of Knowledege? Remarks on Artistic Research", en Art\&Research, 2(2), pp. 1-8. ISSN 1752-6388 [Consulta: 8 marzo 2017]. Disponible en http://www.artandresearch.org.uk/v2n2/pdfs/sheikh.pdf

WHAT, HOW \& FOR WHOM, GARCÉS, M., RAQS MEDIA COLLECTIVE, CAMNIT ER, L., PAGLEN, T., APPELBAUM, J., MOTEN F. y HARNEY, S., y TAMÁS, G.M. 2014. Un saber realmente útil. Madrid: Museo Nacional Centro de Arte Reina Sofía. ISBN 978-84-8026-498-3. 